\title{
Nutritools.org an innovative website including a Food Questionnaire Creator for dietary assessment in health research
}

\author{
M. Warthon-Medina ${ }^{1}$, J. Hooson ${ }^{1}$, N. Hancock ${ }^{1}$, J. Hutchinson ${ }^{1}$, E. Vargas-Garcia ${ }^{1}$, \\ L.E. Gibson ${ }^{1}$, L.A. Bush ${ }^{1}$, K. Greathead ${ }^{1}$, B. Knowles, ${ }^{1}$, B. Margetts, ${ }^{2}$, S. Robinson ${ }^{3,4}$, A. Ness ${ }^{5}$, \\ N.A. Alwan ${ }^{6}$, P.A. Wark ${ }^{7}$, M. Roe ${ }^{8}$, P. Finglas 8 , T. Steer ${ }^{9}$, P. Page ${ }^{9}$, T. Key ${ }^{10}$, L. Johnson ${ }^{11}$, \\ K. Roberts ${ }^{12}$, B. Amoutzopoulos ${ }^{9}$, V.J. Burley ${ }^{1}$, D.C. Greenwood ${ }^{13}$ and J.E. Cade ${ }^{1}$ on behalf of \\ the DIET@NET consortium \\ ${ }^{1}$ Nutritional Epidemiology Group, School of Food Science and Nutrition, University of Leeds, Leeds, LS2 9JT, UK, \\ ${ }^{2}$ Faculty of Medicine, University of Southampton, Southampton SO17 1BJ, UK, ${ }^{3}$ MRC Lifecourse Epidemiology Unit, \\ University of Southampton, Southampton SO16 6YD, UK, ${ }^{4}$ NIHR Southampton Biomedical Research Centre, \\ University of Southampton SO16 6YD, UK, ${ }^{5}$ NIHR Biomedical Research Unit in Nutrition, Diet and Lifestyle, \\ University of Bristol, BS8 1TH, UK, ${ }^{6}$ Academic Unit of Primary Care and Population Sciences, Faculty of Medicine, \\ University of Southampton, SO16 $6 Y D, U K,{ }^{7}$ Centre for Innovative Research Across the Life Course (CIRAL), \\ Coventry University, Coventry CV1 5FB, UK, ${ }^{8}$ Quadram Institute Bioscience, Norwich, NR4 7UA, UK, ${ }^{9}$ MRC Elsie \\ Widdowson Laboratory, Cambridge, CB1 9NL, UK, ${ }^{10}$ Nuffield Department of Population Health Medical Sciences \\ Division, University of Oxford, Oxford OX1 3PA, ${ }^{11}$ Centre for Exercise, Nutrition and Health Sciences, University of \\ Bristol, Bristol, BS8 1TH, UK, ${ }^{12}$ Public Health Section, School of Health and Related Research (ScHARR), \\ University of Sheffield, Sheffield S10 2TN, UK and ${ }^{13}$ Division of Epidemiology \& Biostatistics, School of Medicine, \\ University of Leeds, Leeds LS2 9JT, UK.
}

Accurate diet measurement is challenging and strategies to support researchers in selecting the most appropriate dietary assessment tools (DATs) are required. DIET@NET (DIETary Assessment tools NETwork) partnership aimed to create an online resource that provides guidelines for selecting tools with access to validated DATs.

The Nutritools website ${ }^{(1)}$, www.nutritools.org, was developed using 3 approaches. 1) Creation of Best Practice Guidelines ${ }^{(2)}$, enabling researchers to choose the most appropriate DAT for their work. These were generated using the Delphi method which enabled integration of expert views. 2) Creating an interactive DAT e-library, with the DATs being identified through a systematic review of systematic reviews ${ }^{(3)}$. Bubble charts and summary plots are used to compare DATs. 3) Development of a Food Questionnaire Creator (FQC), an online interface between food tables and the DATs which allows users to create their own food questionnaires. This work was overseen by the DIET@NET partnership. Other useful information includes links to food composition databases and a detailed glossary of terms.

Results from the systematic review of reviews generated information for Nutritools. The website includes 127 international validated tools, of which 63 tools were validated in the UK (with 45 validated from year 2000 onwards). The majority $(\mathrm{n}=34$ ) of the validated tools were food frequency questionnaires, developed from 1981 to 2016. Numbers of foods included ranged from 8-692 items. Five of the 12 dietary recalls included were web-based. Tools were usually validated against another self-reported dietary assessment method, mainly weighed food diaries. More than 1500 papers with non-UK tools were identified, of these, data on 64 international tools and their validation studies were added to Nutritools.

The FQC allows for food questionnaires to be created using data from the UK National Diet and Nutrition Survey (NDNS) Year 6 and the Composition of Foods Integrated Dataset. Results from the NDNS can be used to formulate food questions that capture a large proportion of the nutrients of interest and to inform portion sizes.

In conclusion, Nutritools, www.nutritools.org, is an online platform that hosts international validated and interactive DATs. Researchers can use the interactive Best Practice Guidelines and features in the selection of the most appropriate DAT for their study, and the Food Questionnaire Creator to develop their own online food questionnaires.

This project was funded by the Medical Research Council (MRC) (ref: MR/L02019X/1).

1. Warthon-Medina M, Hooson J, Hancock N, et al. (2017) The Lancet 390, pS94.

2. Cade JE, Warthon-Medina M, Albar S, et al. (2017) BMC Medicine 15(1), p202.

3. Hooson J, Hancock N, Greenwood DC, et al. (2016) Proc Nutr Soc 75(OCE3). 